\title{
TRANSFORMING MANUFACTURING PROCESSES WITH THE HELP OF AI
}

\author{
Keshav Aggarwal \\ Department of Production \& Industrial Engineering, \\ Delhi Technological University, Delhi, India

\section{Shaswat Garg} \\ Department of Mechanical Engineering, \\ Delhi Technological University, Delhi, India

\section{Prakash Budhaulia} \\ Department of Mechanical Engineering, \\ Delhi Technological University, Delhi, India
}

\begin{abstract}
In manufacturing businesses, productivity and cost savings are two important parameters. Technology ease out the load, increase efficiency and mitigate the financial pressure. Modern manufacturing is characterized by high level of automation and technology-driven processes. This digitization of manufacturing has given rise to Industry 4.0 - where cyber-systems, connectivity and data are the key. In this paper we attempt to highlight how each step in the manufacturing process can be changed and made more efficient with the help of technology. To reinforce this fact, examples of various companies have been mentioned which have transformed their supply chains with the help of technology. To better understand this transforming phase in manufacturing industry, we analyzed the role of artificial intelligence in industries, the major issue in implementation of artificial intelligence in manufacturing units, possible ways to overcome these issues and what are the different tasks that can be handled easily with implementation of AI in manufacturing units. With the help of this paper, the reader will get a holistic view of the transforming manufacturing trend and its associated applications in the real world. Certain challenges in the current fourth industrial revolution of manufacturing have also been identified upon which actions can be taken to further improve productivity, cost savings and efficiency.
\end{abstract}

Keywords: Artificial Intelligence, Manufacturing Industry, Smart Manufacturing, Supply Chain Management, Automation, Industry 4.0.

Cite this Article: Keshav Aggarwal, Shaswat Garg and Prakash Budhaulia, Transforming Manufacturing Processes with the Help of AI. International Journal of Mechanical Engineering and Technology. 11(8), 2020, pp. 8-20.

https://iaeme.com/Home/issue/IJMET?Volume $=11 \&$ Issue $=8$ 


\section{INTRODUCTION}

In the age of globalization, the demands for unique and customized products by the customers are pushing the manufacturing industries to rely on automation and machine learning. This has led to the beginning of the fourth industrial revolution, the so-called Industry 4.0. It all began with the first industrial revolution in which transition was made from hand processes to the use of machines specifically from steam power, followed by mass production in second. Industry 4.0 inherits from the third which revolutionized the world with the discovery of computers.

Industry 4.0 makes it possible to gather and exchange data across machines which leads to production of high-quality goods at cheap rates more efficiently, flexibly and quickly. Computers now interconnected with each other can make decisions without any human intervention. Industry 4.0 is acting as a bridge between the digital and physical world. 4IR has a salient role to play towards sustainable growth of small and mid-size industries.

The technologies which form the building blocks of industry 4.0 include cyber-physical systems (CPS), the internet of things (IoT), industrial internet of things (IIOT), cloud computing, cognitive computing and artificial intelligence. Smart manufacturing, light out factories and industrial internet of things form the foundation of industry 4.0. But of all, artificial intelligence is favoured by the innovative manufactures to tackle many of the challenges.

\subsection{Role of AI in Manufacturing and Automation}

AI is basically the technology that allows the computer to think and reason like human beings. AI finds its roots in robotics, computer vision, natural language processing, cloud computing etc. Integration of AI in manufacturing can improve efficiency, flexibility, reduce errors and enable real time optimizing operations. A BCG analysis found that use of AI can reduce producers' conversion costs by up to $20 \%$, with up to $70 \%$ of the cost reduction

resulting from higher workforce productivity. It allows the industries to meet the specific demands of the customers and deliver them at a much shorter time.

$\mathrm{AI}$ is also extensively used to bridge the distance between research and implementation by-

Harnessing useful data: With the help of AI industries are able to process huge pile of data which earlier was impossible to analyse. This helps them to improve customer service and be ahead in fast growing world.

Post-production support: AI allows 24/7 connected service that allows industries to show the customers how their products are to be used and also helps them to detect defects.

Quality Check: Industries use machine vision which make use of AI along with high resolution cameras to detect defects in products like circuit boards which are beyond human vision to detect.

Maintenance: smart factories are making use of AI to detect issues before they arise by tracking and processing the entire manufacturing process.

\section{LITERATURE REVIEW}

A considerable number of studies have investigated the Transformation AI is bringing in the manufacturing industry and the challenges that lie ahead.

Nancey Green Leigh [1] reviewed contributions of AI to the current jobs, their limitations and offered a modified approach. She came to a conclusion that since the Great recession ended, robots improved the employment in manufacturing industry in USA at the metropolitan level 
Bo-hu LI [2] analysed the rapid development of core technologies in the new era of 'Internet plus AI' which is triggering development in the manufacturing industry. $\mathrm{He}$ proposed new models, means and forms of intelligent manufacturing, intelligent manufacturing system architecture based on the integration of AI technology with information communications, manufacturing, and related product technology.

Sameer Mittal [3] presented the building blocks frequently using for SM adoption. He found that for the manufacturers that are inclined toward adopting SM intelligent control, data analytics, IT-based production management systems (e.g., ERP, CAx, etc.), smart products/parts/materials are the most commonly used building blocks.

S.P. Leo Kumar [4] reviewed the applications of AI in Computer Aided Process Planning (CAPP) and manufacturing. He addressed the present review work by analysing existing review articles. Finally, they identified the research gaps ad presented the possible future research directions.

Kamran Mahroof [5] researched on the drawbacks and opportunities of AI within the warehouse of a major retailer. His findings revealed the challenges resulting from the shortage of both skill and mind-set of operational management.

Gideon Cohen [6] described the knowledge-base and inference-engine which were developed to determine various shop-floor operational strategies to achieve maximum efficiency of machines.

Simon Hagemann [7] presented a novel AI methodology capable of generating initial production configurations base. He concluded that to ensure high efficiency in the automotive industry AI techniques are vital.

Helen H. Lou [8] introduced a proactive Quality Control approach by resorting artificial intelligence and engineering fundamental. They came to the conclusion that Proactive QC is becoming more and more attractive in the manufacturing industries due to increased economic and environmental pressure.

S. Gallego García [9] reviewed the impact of new capabilities due I4.0 on production and maintenance management tasks in order to provide an impulse to current manufacturing companies.

Yuval Cohen [10] reviewed the challenges faced by the manufacturing and assembly systems and their readiness to adopt Industry 4.0 and. It also focuses on the most promising future developments and evolution of such production systems.

Pinar Urhal [11] presented and discussed the leading additive manufacturing methods that can be used with a robotic system. They came to the conclusion that current additive manufacturing systems have great potential to reduce time to market, increasing customisation, widening the design option compared to traditional methods.

Di Wu [12] tried to understand what knowledge is and what kinds of knowledge can be obtained and applied in a design. They came to the conclusion that to tackle challenging optimization problems and to further improve the efficacy of design optimization, it seems imperative to let go the assumption of black-box functions, but rather incorporating existing knowledge in optimization.

Max Busch [13] studied that various complexity in production planning and control, can be solved with the help of techniques of AI and digitization of manufacturing. For this he proposed a model named as maturity model. The maturity model is based on results from the research project WerkPriMa.

Mike Keen [14] reviewed that AI is helpful in manufacturing by improving quality, reducing cost, and to speed up design and manufacturing process. This can be done with the 
help of Quality Design Expert System (QDES), Technical Information Engineering System (TIES), Vibrational Analysis in Rotating Machines, Trailer configure.

Stephan Matzka [15] reviewed that quality prediction can be done in manufacturing process using machine learning process. This can be using AI algorithm (in case of screw fastening process is determined using a torque versus rotation angle (or time diagram).

Ge Meng [16] researched on e-intelligence maintenance system for manufacturing industrial theory which is in progressing, the NET framework is progressing and the Web Services which is based on XML is applied widely.

Julian SK Tan [17] researched on how quality analysis can be achieved in big data supply chain. Data is collected using HIGH PERFORMANCE COMPUTING centers and use them to distribute HADOOP installations and how IoT devices at the point of data collection can be used to make fastening the process of analytics and advanced it.

Yifang Ma [18] researched on how artificial intelligence can be used in development of autonomous vehicles. This can be done by using various methods like big data, HPC, and high-resolution digital map for enhanced data collection and processing AR/VR which can be used to enhanced the process of constructing accelerated test scenarios, 5G for low latency connections among AV's.

B.F. Bashir, S.J. Steiner [19] researched on how an AI based simulation system to improve shop-floor efficiency and to reduce production cost this is done by using a method which has four sub systems. The four sub-systems of the model are as indicated: User interface, Process Routing, Simulation, and Control. Information arrives into the system, which can be in the form of product demand and/or feedback information.

Wesam Salah Alaloul, M.S. Liew [20] researched how industry 4.0 concept can be used in construction industry. Technologies such as BIM, cloud computing, and modularization have helped significantly in developing technologies such as augmented, virtual and mixed reality which can be used to influence the sustainability of the industry.

Roland W. Scholz [21] researched and explained how digital threats can be controlled. This can be done through a multi-level actor analysis, identifying strengths and weaknesses of organizations, constructing digital threat scenarios and provides judgment-based expert assessments on the organization's vulnerability

R. Satish [22] researched on how technology strategy can be used to improve safety management. Sensors collect vast amounts of data, and that information is then interpreted by artificial intelligence (AI). This optimizes the production line and creates synergies across the facility and provides a great thrust on Safety.

Hong Seok Park [23] researched on product quality. They used AI based on injection Moulding process in plastic industry. This can be done using real time AI based control of process parameters in injection moulding cycle.

T. Santos [24] researched how technology can be used for maintenance management in the food industry. It can be done with the help of the application of a methodology of Reliability Centred Maintenance (RCM), revision of Preventive Maintenance Plans (PMP), integration of critical asset in Computerized Maintenance Management System (CMMS) and many other.

Sidharth Baskaran [25] researched how siemens process can be used in automotive assembly line. A digital twin of a mobile robot designed to provide physical assistance to the human to perform the assembly operation is introduced. 
Robert Joppen [26] researched on the optimization of production management process. It describes how the conflict of objectives can be analysed systematically and a reasonable operational status can be derived.

Muhammed Zekeriya Gunduz [27] researched cyber security, threats and potential solutions. The smart grid is one of the most significant applications of the Internet of Things (IoT) based smart grid systems are critical infrastructures, also they have complex architectures and include critical devices.

\section{REALITY OF AI IN INDUSTRY}

\subsection{Gap between Ambition and Reality}

Industries all around the world are looking forward to make use of AI in manufacturing units increase productivity and better product quality. Countries like China, India and Singapore on average are looking more forward to implement AI in industries as shown in Fig (1)[28].

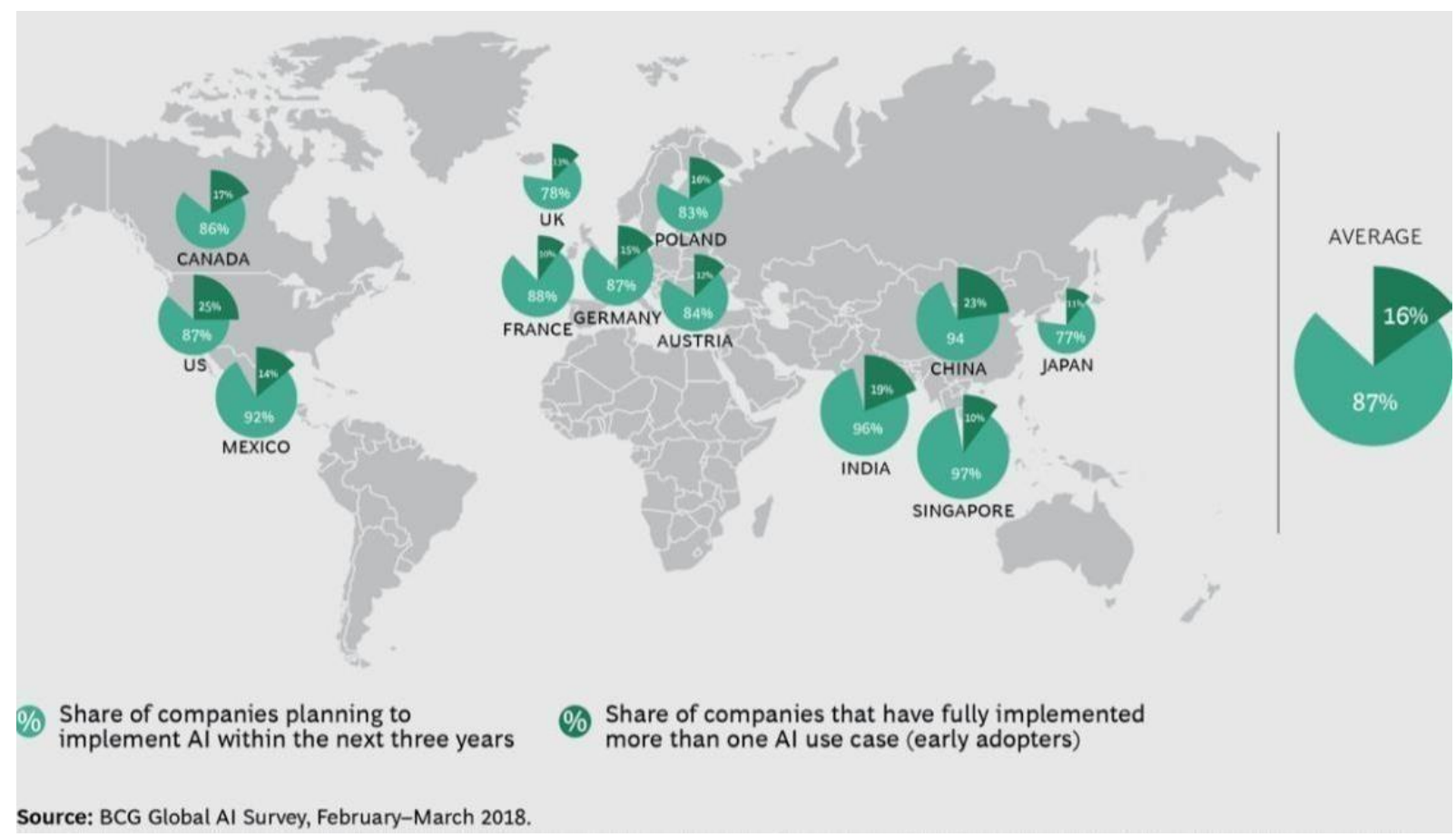

Figure 1 Gap Existing between AI Ambition and Reality

Many companies know the benefits of $\mathrm{AI}$ in industries and are planning to bring this in the production factories but do not have proper roadmap to implement this. They do not have a proper planning, investments and implementation to meet up their ambitions. According to a survey $87 \%$ of companies want to implement $\mathrm{AI}$ in their industries within short coming years but, only $28 \%$ take a proper planning to implement it, while $72 \%$ do not have a proper planning on how to implement it while $27 \%$ have rough ideas on how to implement it while $13 \%$ do not consider AI importance in factories. Gap between ambition and reality in various industries has been depicted in Fig (2)[28].

Thus, there need to be a definite and effective planning to implement AI in industries. In past years only $50 \%$ of companies have successfully achieved AI in their industry while only $16 \%$ have adopted more than one AI cases in their industries. Surveys in 12 countries show that companies that early implement AI in their factories are $25 \%$ in United States of America, $23 \%$ in China, $19 \%$ in India, 11\% in Japan, 10\% in Singapore, 10\% in France, and in Germany $15 \%$. 


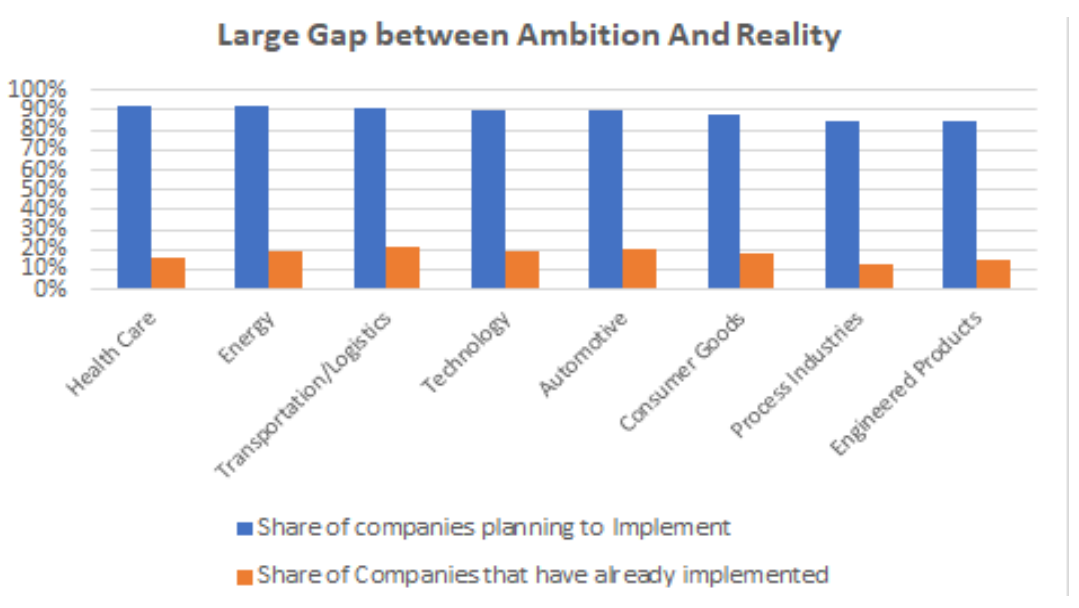

Figure 2 Gap Existing between AI Ambition and Reality In various sectors

\subsection{Closing this Gap}

Since the introduction of AI, every industry wants to adopt it and increase their effectiveness of productivity but small industries do take time to adopt it, due to high setup cost and not having proper roadmap how to implement it in their industry. Due to new technologies and development it has become easy to adopt this technology in manufacturing unit. There are some measures which can help in implementing AI in industry.

Strategies should be made on how to generate investments at each level and in which particular field of business AI should be adopted which result in ease of manufacturing. Company should have good employee competencies to handle the skills required work with AI, they should be skillful in data management, analytics and other competencies. For such skill employee can get it within the company or outside the company. From data around one in four $(29 \%)$ of companies have increased the number of employees dedicated to AI and nearly half $47 \%$ will do the same in coming years. Testing should be done at small scale and then be implemented at large practices for successful and effective use of AI in industry. Among the different technologies of artificial intelligence, the one which are being usedthe most are extensive use of computer vision cameras which are used in machine inspection, implementation of Industrial Internet of Thing (IIoT), and the use of big data. With thehelp of other technologies too industries are revolutionizing.

Developments are done to improve the technologies in AI and make it more cost effective, more accurate and more productive. The upcoming technology will help in increasing production, bringing out the best quality for a product and helping in creating a better and safe environment of work.

\section{IMPLEMENTATION OF AI IN SUPPLY CHAIN}

Today AI is more accessible than ever. The manufacturing industry is beginning to embrace AI in their products and services. AI is finding its roots in all the segments of Supply chain like Product R\&D, Resource Planning etc. Ways through which AI is transforming various sector of Supply chain are listed below-

\subsection{Product R\&D}

$\mathrm{AI}$ is transforming the research and development (R\&D) by accelerating the development of new products and services by continuous discovery, accessibility and application of data to improve the standard of living. Any company that innovates through R\&D are bound to lead the market and even may monopolize it. 
AI can transform the $R \& D$ process by accelerating the development of product by identifying the proper materials for the finished product, identifying any possible failure in parts in the near future, accelerating product data exploration.

\subsection{Resource Planning and Sourcing-}

The manufacturing industry is highly competitive and dynamic which makes it crucial to integrate it with integrated solution which can reduce cost, increase efficiency, sales and profitability but most importantly allowing the company to make accurate, informed and strategic decisions. This is where enterprise resource planning (ERP) steps in. It consists of hardware and software system working together to supervise the success of design and production of products followed by delivery to end user.

Integrating AI with ERP enable companies to improve their operational efficiency by using machine learning and natural language interface. SAP Leonardo is good example of AI driven ERP system which includes several microservices integrated with a cloud platform. AI improves ERP in the following ways [29]-

Advance Analytics: The ability of AI to work with massive amount of data allows real time, accurate data insights. For example- by analysing the behaviour of different type of customers can allow you to manufacture products and services that is meant for a certain audience.

Forecasting: By processing the old data AI can make predictions about the future.AI along with reducing the cost of forecasting can also make forecasting accurate. It reduces the risk of overproduction or underproduction when you manufacture the accurate number of products [30].

Financial Management: AI can improve transaction-processing efficiency, verify reports with accuracy and can also predict future financial results based on trends and market data [31].

Customer Service: AI based on performance evaluation and qualification of employees can assist with planning and schedule service calls.

Production processes: ERP integrated with AI can be used to detect inefficient processes and suggest ways to improve it thereby cutting cost and minimizing the wastage of resources.

\subsection{Machining, Production, \& Assembly}

As the world have changed and so has manufacturing. As the standards of living are improving so is the cost of converting raw material to products. With the growing expectations of the customers for personalization and flexibility AI is poised to play a critical role. Therefore, to meet the needs of the customers cyber physical systems like industrial robots and $3 \mathrm{D}$ printers are becoming common in the modern industry.

Cobots (Collaborative robots) are most used. They learn first by being moved manually and then by copying the movement. They are collaborative because they work alongside humans. Airplane manufacture Airbus uses mobile robots which work alongside humans to drill thousands of holes into passenger jets. A new wave of technology called the Intelligent Edge System is taking the manufacturing industry by storm. It is a fast, real time control system for network linked robot and machine tools. By using deep learning AI technology these systems will learn and become smarter as linked machines manufacture products.

$3 \mathrm{D}$ printing is a game changing technology constantly evolving itself. Combination of AI with 3D printing is now widely used by companies for manufacturing. AI can be used to create more efficient CAD models. Autodesk developed Dream catcher a tool allowing to work on regenerative designs. Hundreds of designs can be created within hours using this software. Also, AI can be used to detect defects in 3D model which could make it non- 
printable. To spot microscopic cracks in machine parts General Electric's GE labs in New York began to developed a computer vision technology.

Therefore, by incorporating AI in assembly line can reduce error, make manufacturing efficient and improve the quality of product.

\subsection{Quality Assurance}

In the fast-evolving market the companies which can deliver quality products faster than its competitors have significant advantage over others. At the same time complexity and proneness to error has massively increased. Therefore, QA must evolve to meet the demands of the customers while maintaining the quality of service. AI can improve QA by imagining assembly lines as interconnected, data driven and autonomous networks. If even a slight deviation from the original value is detected by the sensors which they send to the users so that the issue can be dealt. The system can also learn as the time goes on and therefore making changes on its own.

Using QA with autonomous, self-learning AI can Spot early problems in production, identify slowdowns and potential failure before they occur, save resources and time thereby improving efficiency.

\subsection{Warehousing}

In the last few years, the warehouse industry has seen a lot of automation. By the year 2020 AI might be transforming the warehouse operations completely. Smart warehouse forms an ecosystem of interconnected technologies where AI governs the entire operation, from supply to delivery. To reduce error in warehousing, AI can be used to identify and sort, process, package goods and pull them for shipment [34].

Ways through which warehousing is expected to be affected by AI are [35][36]-

Communication: For smooth functioning of day-to-day jobs the workers should be able to communicate in an efficient manner in order to achieve targets and fulfil the task successfully. With the use of AI algorithms, the systems can communicate at a much faster rate than humans. By the means of Wireless, I-O Link and Fieldbus data communications all the elements of the system can communicate with each other.

Warehouse Logistics: AI can help in optimizing in logistics by calculating the number of packets needed to be handled on a given day and how much equipment is required. Earlier it all relied on variables such as operator skill level and SKU (stock keeping units). Introduction of machine learning algorithm has helped in stock movement forecasting and management of material. In this way operator error and processing time can be reduced thereby increasing productivity and efficiency.

Inventory: With the help of AI, money which was previously spent on inventory can now be invested in other business growth opportunities. Bar code scanners are now replaced by RFID (Radio frequency identification) for organization and control of inventory. Using AI speed and volume of order to be processed can be adjusted, therefore increasing the overall productivity.

Robots: Another way in which AI is transforming warehouse management is with the use of robots. They can carry heavy goods and transport them to the desired location in fraction of time as compared to human operatives. With the help of machine learning algorithms bots can efficiently pack the products efficiently, select the most efficient picking and slotting routes.

Ocado, a British online supermarket, designs highly automated warehouses. Crates are stacked in piles with the position of each decides by an algorithm- rare purchases are placed 
on the bottom of the stack. Crates are grabbed by bots which manoeuvre around the warehouse for 24 hours while humans pack and unpack the crates.

\subsection{Labour Augmentation \& Management-}

Since the birth of AI there has been a fear in the hearts of people "what effect AI will have on the job market". But rather than consuming jobs AI will improve the quality of skillset of workers. Impact of AI on jobs is depicted in Fig (3). A 2018 study by the accountancygiant $\mathrm{PwC}$ forecasted that machines would create as many new jobs in the UK as they destroyed over the next 20 years - although it said there would be "winners and losers" by industry sector, and many roles were likely to change [32]. Thus, in the future rather than AI taking jobs, humans and AI will work in unison.

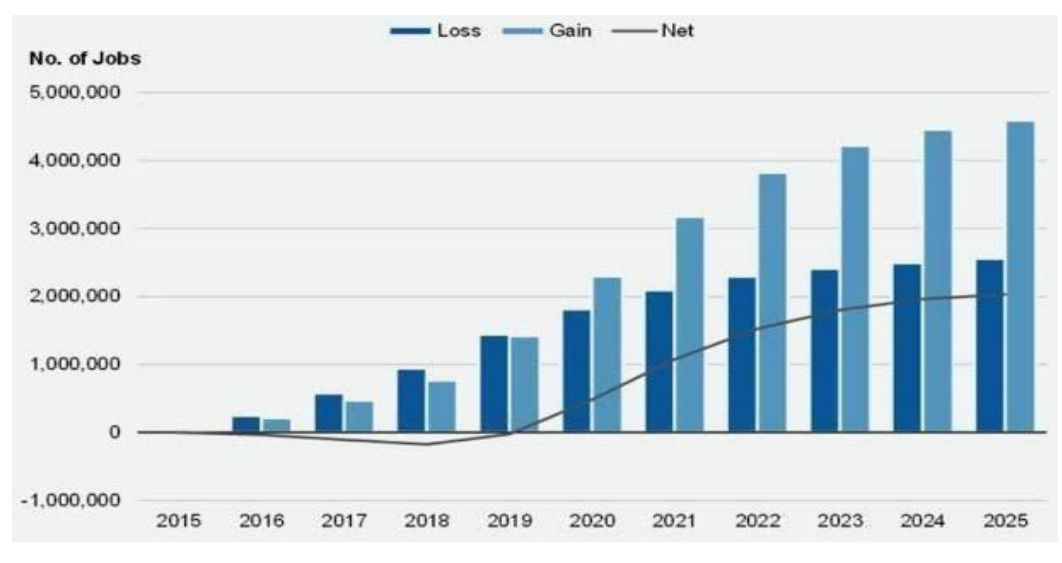

Figure 3 The impact of AI Automation on jobs

A very good example is of the exoskeletons. By developing a supportive techno-carapace, they have empowered people to lift weights and achieve performances that were initially unthinkable. In addition, chatbots are widely used by companies for answering customers queries and scheduling meeting [33].

\subsection{Transportation and Logistics}

This sector forms an integral part of manufacturing and $\mathrm{AI}$ is finding its roots to revolutionize this sector. Autonomous trucks are highly in demand for transportation of goods from suppliers to producers. Developments are done in designing such a system where truck can trace each other mark their presence with the sensors inbuilt in them and automate the acceleration and braking system, which increases the safety for the driver as well of the products from getting being damaged from accidents.

\section{EXAMPLES OF INDUSTRIES WHERE AI IS IMPLEMENTED}

In march 2016, Siemens launched Mindsphere. Mindsphere is a smart cloud for industry which allows machine manufacturers to monitor machines for fleets for service purposes throughout the world.

Lamborghini recently established a new production facility in Sant 'Agata Bolognese with an assembly line dedicated in Urus, a finishing department for all Lamborghini models and new office. Integration of new production technologies supports the collaboration of humans and robots thereby improving the assembly and maintenance activities. These robots are designed ergonomically for the workers using it. Also, tiny mobile robots called robotini are used for simple chores such as transporting components and tools to different workstations. It helped the company to increase its production and efficiency [37]. 
Adidas is investing on what it calls as 'Speed factory'. With the target of reducing the manufacturing and production period Adidas is embracing supply chain digitization by using 3D-design, 3D printing programs and state of the art robotics. With the help of speed factory, they will be able to shorten the time of prototyping from several months to a couple of days. The facility pairs human workforce with advanced technologies to manufacture "athlete datadriven designs, radical accelerated footwear production, open-source co-creation, and hyperflexible localised manufacturing".

Hirotec Group a Japanese automotive components manufacturer adopted machine learning and AI to tackle the perennial problem of unplanned downtime. To ensure continuous operation and to minimise unplanned downtime it combined HPE's Edgeline IoT technology, developed to crunch data out on the edge of IoT networks, with PTC's Thingworx IoT platform and KEPServerEX agent in order to collect and analyse data from the factory floor. The company is progressing towards light out manufacturing with the use of Yaskawa Motoman dual-arm robots mounted on Otto Motors self-driving vehicles in its production process as a way of realising that vision [38].

Nike collaborated Grabit to use their robot system electro adhesion technology to automate the task of fine material handling. With the help of Grabit's electroadhesive gripper, robots can stack materials like leather, composite fibre etc. Nike uses Grabit's Stackit material handling robot system to produce up to 600 pairs of shoes in an eight-hour shift. To innovate its supply chain Nike partnered with Flex, a world class manufacturer. Partnership between Nike and Flex will enable the product to reach consumers more quickly [39].

Bosch is striving to automate its production line. To assemble machines its production line is made up of three automatic and two manual modules. These modules use RFID scanners to determine the control to be produced. They make use Manufacturing Execution System (MES)-IT Shop floor Solutions to control their line operations. MES provides real time information about the work pieces and production steps for transparent analysis, planning and monitoring of assembly [40].

\section{CONCLUSION}

Industry 4.0 is one of the most emerging concepts used by the industries to enhance their production capacity, decrease their product cost, create a safer environment for work. In this paper we reviewed how implementing $\mathrm{AI}$ in industries can revolutionize the production line, supply chain and different ways of production in manufacturing units. We reviewed that implementing AI in industries is beneficiary but due to its high investment cost and requirement of a good knowledgeable team which helps in setup of technology in manufacturing units, it is currently limited to only big firms. We also reviewed that AI can immensely help manufacturing units by providing assistance in research and development as the entire world data can be accessed easily, it also helps production line by figuring out the best way to manufacture the product, it also helps in quality assurance by using different techniques to detect any defect in products, it also helps in creating a safer environment for work by keeping an eye check on all the machinery and systems and alert in case of any mishappening. We also figured out a lot of medium and small-scale industries want to implement $\mathrm{AI}$ in their industries but not having a proper roadmap on its implication they face difficulties. We also figured out what are gaps in implementation of AI and how these gaps can be filled. Thus, implementing AI in manufacturing units can help industries in various ways and bring out best from them and revolutionize the industries. 


\section{CHALLENGES AHEAD}

The adoption of artificial intelligence in manufacturing industry can help in dealing great challenges with ease. For more implementation of artificial intelligence in industries, still a lot of work needs to be done. The biggest challenge for implementation of artificial intelligence was its cost for setup, work need to be done so that the cost of technologies can be reduced while maintaining high accuracy. Investment is a major cause which holds the hand of industrialist to implement $\mathrm{AI}$ in their industries. There is always a risk to invest a huge amount at any technology, small manufacturers always hesitate to do this as theywant return of investment faster at any technology that they have implemented in theirindustry.

Lack of knowledge about new technologies as the development is taking place at a faster pace in field of technology and companies need to be informed and updated about all the developments going around. This increase the burden on manufacturers and increase their problems to cope up with the advancement taking place in the technology

There is still a lot of space for AI in deciding the product for industry that could manufacture as per consumer choice, as AI will collect data from customers and by using algorithms will help in deciding factors. There is a lot of work to be done to create a safer environment for work with the help of AI.

Using AI in manufacturing units there should be a proper recording of all the information from all the stages and departments of manufacturing units so that pre decisions can be made with the help of algorithms of AI. Artificial intelligence can also be used to reduce the time, technique and steps for production of goods from the help of all the information which is collected to make decisions [41].

Implementation of AI in industry also deals with threats from cyber-attacks, so a more secure and advance software need to be developed to protect from this threat [42].

Thus, there is a lot of scope and work that need to be done in implementation of artificial intelligence in manufacturing units with fast development and progress in how AI can be implemented in industry we will surely be able to make reach of artificial intelligence in every industry.

\section{REFERENCES}

[1] Leigh N G, Kraft B, Lee H (2019), Robots, skill demand and manufacturing in US regional labour markets, Cambridge Journal of Regions, Economy and Society.

[2] Li B. hu, Hou B. cun, Yu W. tao, Lu X. bing, Yang, C. wei. (2017), Applications of artificial intelligence in intelligent manufacturing: a review, In Frontiers of Information Technology and Electronic Engineering, pp. 86-96, 18(1)

[3] Mittal S, Khan M A, Romero D, Wuest T (2019), Building blocks for adopting smart manufacturing, Procedia Manufacturing, pp. 978-985,34

[4] Leo Kumar S. P. (2017). State of The Art-Intense Review on Artificial Intelligence Systems Application in Process Planning and Manufacturing, Engineering Applications of Artificial Intelligence, pp. 294-329,65

[5] Mahroof K (2019), A human-centric perspective exploring the readiness towards smart warehousing: The case of a large retail distribution warehouse, International Journal of Information Management, pp. 176-190, 45

[6] Cohen G (1989), Using AI techniques to optimize manufacturing shop-floor operations, Engineering Applications of Artificial Intelligence, pp. 238-246,2(3)

[7] Hagemann S, Sünnetcioglu A, Stark R (2019), Hybrid artificial intelligence system for the design of highly-automated production systems, Procedia Manufacturing, pp. 160-166,28 
[8] Lou H H, Huang Y L (2003), Hierarchical decision making for proactive quality control: System development for defect reduction in automotive coating operations. Engineering Applications of Artificial Intelligence, pp. 237-250, 16(3)

[9] García G S, García G M (2019), Industry 4.0 implications in production and maintenance management: An overview, 8th Manufacturing Engineering Society International Conference 2019, pp. 415-422, Madrid, Spain

[10] Cohen Y, Faccio M, Pilati F, Yao X (2019), Design and management of digital manufacturing and assembly systems in the Industry 4.0 era, In International Journal of Advanced Manufacturing Technology, pp. 3565-3577, 105(9)

[11] Urhal P, Weightman A, Diver C, Bartolo P (2019), Robot assisted additive manufacturing: A review, Robotics and Computer-Integrated Manufacturing, pp. 335-345,59

[12] Wu D, Gary Wang G (2020), Knowledge-Assisted Optimization for Large-Scale Design Problems: A Review and Proposition, Journal of Mechanical Design, 142(1).

[13] Busch M, Schuh G, Kelzenberg C, de Lange J (2019). Short Paper: Development of Production Planning and Control through the Empowerment of Artificial Intelligence. 2019 Second International Conference on Artificial Intelligence for Industries (AI4I), pp. 115-118.

[14] Keen M. Successful Applications of AI in Manufacturing Industry.

[15] Matzka S (2018), Using Process Quality Prediction to increase Resource Efficiency in Manufacturing Processes, 2018 First International Conference on Artificial Intelligence for Industries, Laguna Hills, CA, USA

[16] Meng G, Yanli J (2011). Research on e-intelligence maintenance system for manufacturing industrials. Proceedings - 2011 International Conference on Internet Computing and Information Services, pp. 457-458, ICICIS 2011,

[17] https://ieeexplore.ieee.org/document/7848697

[18] Ma Y, Wang Z, Yang H, Yang L (2020). Artificial Intelligence Applications in the Development of Autonomous Vehicles: A Survey, 7(2)

[19] Bashir B F, Steiner S J, An A.I. based simulation system to improve shop-floor efficiency and to reduce production cost.

[20] Alaloul W S, Liew M S, Zawawi N A W A, Kennedy I B (2019). Industrial Revolution 4.0 in the construction industry: Challenges and opportunities for stakeholders. Ain Shams Engineering Journal.

[21] Scholz R W, Czichos R, Parycek P, Lampoltshammer T J (2020). Organizational vulnerability of digital threats: A first validation of an assessment method. European Journal of Operational Research, pp. 627-643, 282(2)

[22] Satish R, Murugabhoopathy K, Rajendhiran N, Vijayan, V. (2020). Technology strategy for improved safety management in steel industry. Materials Today: Proceedings.

[23] Park H S, Phuong D X, Kumar S (2019). AI based injection molding process for consistent product quality. Procedia Manufacturing, pp. 102-106,28

[24] Santos T, Silva F J G, Ramos S F, Campilho R D S G, Ferreira L P (2019). Asset Priority Setting for Maintenance Management in the Food Industry. Procedia Manufacturing, pp. $1623-1633,38$

[25] Baskaran S, Niaki F A, Tomaszewski M, Gill J S, Chen Y, Jia Y, Mears L, Krovi V (2019). Digital human and robot simulation in automotive assembly using siemens process simulate: A feasibility study. Procedia Manufacturing, pp. 986-994,34

[26] Joppen R, von Enzberg S, Kuhn A, Dumitrescu R (2019). A practical Framework for the Optimization of Production Management Processes. Procedia Manufacturing, pp.406-413,33 
[27] Gunduz M Z, Das, R. (2020). Cyber-security on smart grid: Threats and potential solutions, Computer Networks, 169

[28] Bcg Homepage, https://www.bcg.com/en-in/publications/2018/artificial-intelligence-factoryfuture.aspx, last accessed 2020/2/12

[29] Panorama Consulting Group Homepage, https://www.panorama-consulting.com/howartificial- intelligence-improves-erp-software/, last accessed 2020/2/12

[30] Infopulse Homepage, https://www.infopulse.com/blog/the-main-benefits-and-challenges-ofindustry-4-0-adoption-in-manufacturing/, last accessed 2020/02/12

[31] The manufacturer Homepage, https://www.themanufacturer.com/articles/power-artificialintelligence-manufacturing/, last accessed 2020/02/12

[32] Raconteur Homepage, https://www.raconteur.net/technology/ai-human-augmentation, last accessed 2020/2/12

[33] Horses for Sources Homepage, https://www.horsesforsources.com/gartner_fail_automationAI_080418, last accessed 2020/2/12 ifr Homepage, https://ifr.org/ifr-pressreleases/news/global-industrial-robot-sales-doubled-over- the-past-five-years, last accessed $2020 / 2 / 12$

[34] Cbinsights Homepage, https://www.cbinsights.com/research/future-factory-manufacturingtech- trends/, last accessed 2020/2/12

[35] Warehousing Logistics International Homepage, https://www.warehousinglogisticsinternational.com/how-will-ai-transform-the-smartwarehouse/, last accessed 2020/2/12

[36] Lamborghini Homepage, https://www.lamborghini.com/en-en/news/lamborghini- awardwinning-factory-future, last accessed 2020/02/13

[37] Otto motors Homepage, https://ottomotors.com/blog/manufacturing-data-industry-4-0, last accessed 2020/02/13

[38] Nike Homepage, https://news.nike.com/news/nike-s-manufacturing-revolution- acceleratedby-new-partnership-with-flex, last accessed 2020/02/13

[39] Bosch Homepage, https://www.bosch.com/stories/industry-4-0-production-line/, last accessed 2020/02/13

[40] Datanami Homepage, https://www.datanami.com/2019/04/25/big-data-challenges-of-industry4- 0/, last accessed 2020/02/12

[41] Challenges Homepage, https://www.challenge.org/industry-4-0-3-3/challenges/,last accessed 2020/02/12 